\title{
How many green turtles nest on Aldabra?
}

\author{
Wendy Seabrook
}

The population of female green turtles Chelonia mydas nesting on Aldabra Atoll has been claimed to be the largest in the Seychelles. Several surveys have been undertaken of the numbers nesting, but none has managed to provide reliable estimates of the size of the nesting population.

Aldabra Atoll $\left(9.5^{\circ} \mathrm{S}, 46.5^{\circ} \mathrm{E}\right)$, lying $1150 \mathrm{~km}$ south-west of the main granitic Seychelles group of islands and north-west of Madagascar, is a World Heritage Site and one of the finest examples in the world of a raised coral atoll ecosystem (Stoddart and Savy, 1983). Green turtles were exploited commercially on the Atoll from the late nineteenth century, when a fishing settlement was established, to 1968, when a total ban on the capture of green turtles was imposed in the Seychelles. Today nesting occurs on at least 48 of the 56 beaches (Seabrook, 1989) distributed along the approximately $80 \mathrm{~km}$ of coastline.
The first estimates of the number of female green turtles nesting on Aldabra were provided in the late 1960s. Fewer than 1000 individuals were believed to nest annually then (Hirth and Carr, 1970; Frazier, 1971), and only 700 in 1975/76 (Gibson, 1979). More recently Mortimer (1985) reported that 1900-2500 nested in 1981, 2030-2675 in 1982 and 2210-2915 in 1983. These estimates are revised in a later publication (882-1556 in 1981, 946-1598 in $1982,974-1896$ in 1983), which also gives estimates for $1984(1083-2148)$ and 1985 (820-1452) (Mortimer, 1988), but we are not told the reason for the revision.

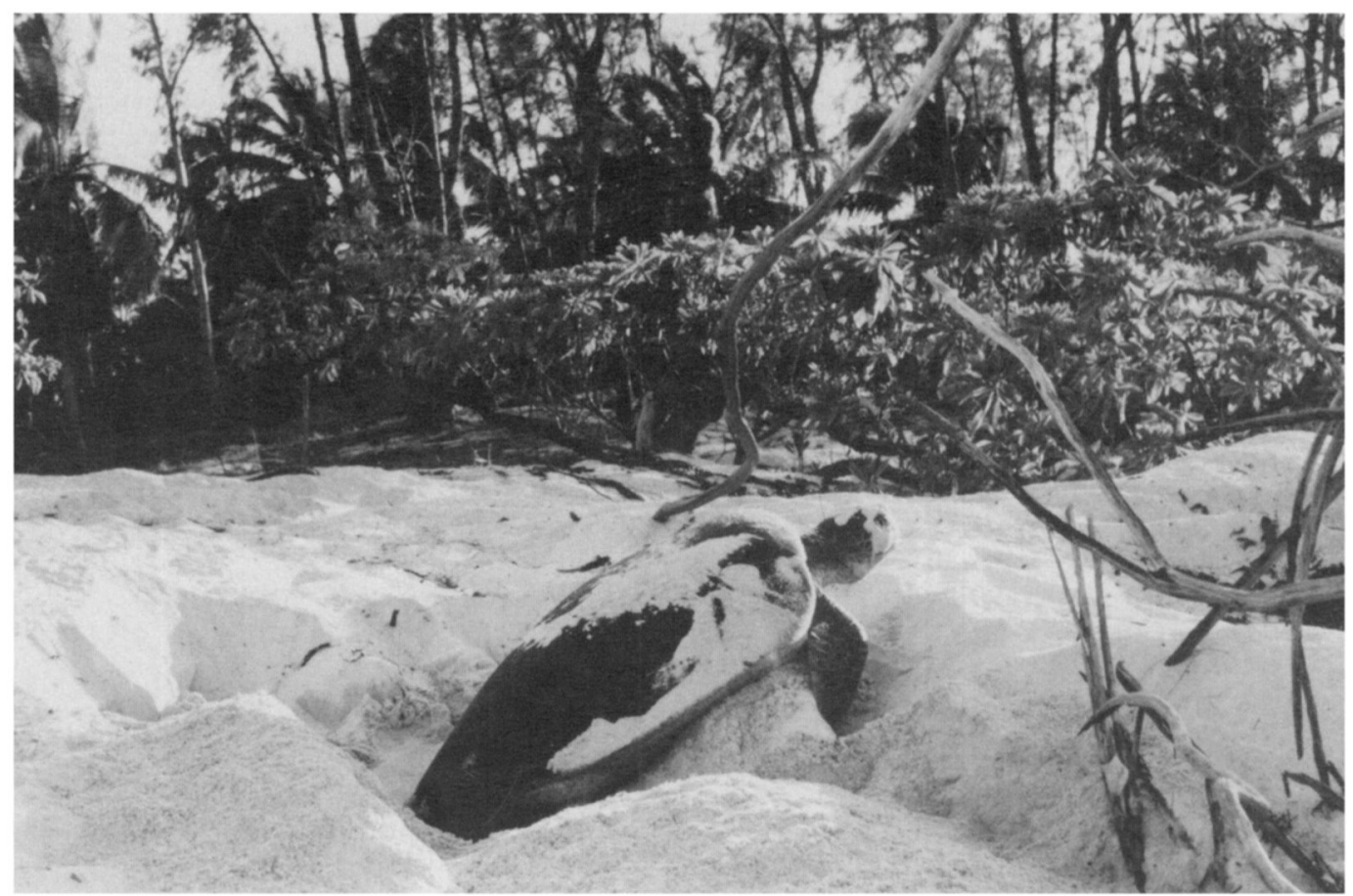

Green turtle completing its nest (W. Seabrook). 


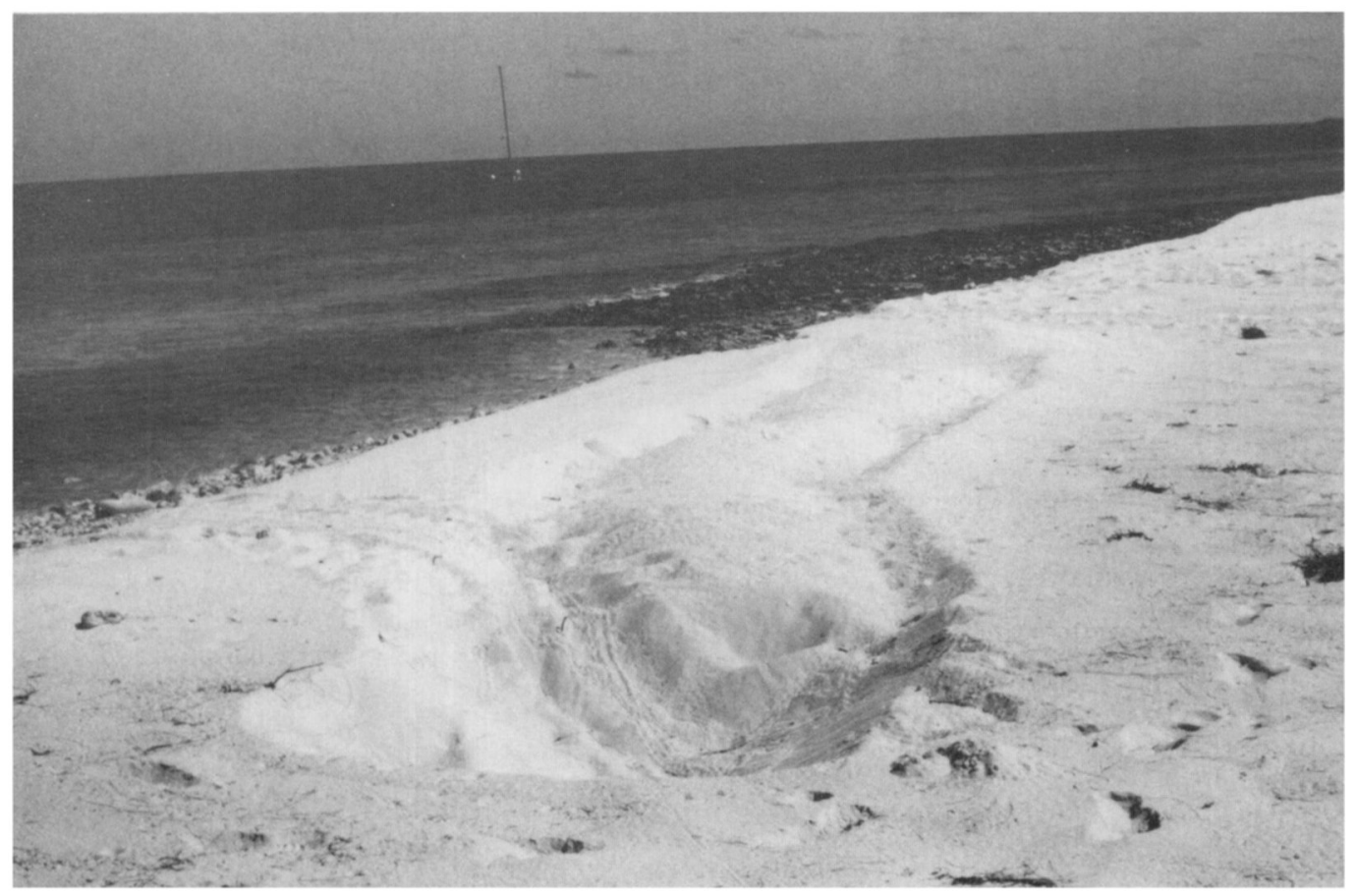

Green turtle nest after turtle has left (W. Seabrook).

Estimates of the number of female marine turtles nesting at a rookery can be obtained using multiple capture-recapture techniques (Le Gall et al., 1986) or from estimates of the number of nests dug, when the average number of nests each female constructs each year is known (Meylan, 1982). Neither Hirth and Carr (1970) nor Frazier (1971) had sufficient information on which to base their estimates. The former's originated from a brief observational visit to the Atoll. Frazier (1971) gathered data on the number of nests dug, but stated that he did not have enough data with which to make a reliable estimate. The more recent estimates (Gibson, 1979; Mortimer, 1985, 1988) were derived from the numbers of nests dug. While these surveys were more intensive, neither surveyed the number of nests dug directly, nor had sufficient observational information with which to estimate the average number of nests dug per female.

Gibson (1979) and Mortimer (1985, 1988) derived their nest estimates from the results of surveys of tracks made by female turtles emerging on the beaches, and Gibson also used the number of holes dug by nesting females, both those associated with successful nests and those made during unsuccessful nesting attempts. These results were converted to estimates of the number of nests dug using ratios derived from limited observations of individual turtles and fresh tracks. Green turtles nesting on Aldabra regularly emerge several times and dig more than one hole before successfully constructing a nest (Frazier, 1976; Mortimer, 1988; Seabrook, 1989).

Recent work on Aldabra has shown that there is considerable variability in the nest:emergent and nest:pit ratios, both between months and between different groups of beaches (Seabrook, 1989). Gibson takes no account of this variability, and while Mortimer (1988) does for groups of beaches, insufficient information was obtained to predict what the ratios would be during drier periods, when drier sand makes nest construction more difficult (Bustard and Greenham, 1968). Instead 
'the number $125 \%$ was arbitrarily chosen as a reasonable factor by which to multiply the figures' $^{\prime}$ calculated for the wet season. While there are considerably more emergences during the dry season (Gibson, 1979; Mortimer, 1984, 1988; Seabrook, 1989), contrary to Gibson's (1979) and Mortimer's (1988) extrapolations, fewer nests are actually dug during this season (Seabrook, 1989). Careful reading of the three papers (Gibson, 1979 and Mortimer, 1985, 1988), also illustrates that the survey coverage was not adequate. Gibson (1979) had also to rely on track and nest hole longevity estimates, and confounded the results by not distinguishing between holes associated with actual nests and those not.

The average number of nests individual female green turtles construct per year at different rookeries has been reported to range between 3 and 6 (Hendrickson, 1958; Le Gall et al. 1986) In spite of this considerable variability, to estimate the number of female green turtles nesting at the Aldabran rookery, Gibson (1979) used a frequency of 3, while Mortimer (1988) considered that a frequency of 5.5 , based on tagging data obtained in Australia, would provide a 'reasonable estimate' We are not told which frequency Mortimer (1985) used to obtain her earlier estimates. The nesting frequencies used by Gibson (1979) and Mortimer (1988) could be used to compare the relative numbers nesting on Aldabra between years, but this assumes that the actual unknown frequency does not vary between years.

It is apparent, therefore, that despite the considerable research effort that has been invested in attempting to estimate the number of female green turtles nesting on Aldabra (including those of the author [unpubl. data]), no reliable estimates have been provided. It should be recognized that there are considerable logistical difficulties involved with this type of research on Aldabra: beaches are isolated and difficult to reach and aerial survey coverage cannot be provided. Nevertheless, estimates of the number of females nesting at a given rookery should be provided only with clear qualifications as to their limitations, especially if there is the chance that the infor- mation may be used to justify exploitation or develop management plans.

\section{Acknowledgments}

My thanks to Professor P. Racey for the use of the facilities at the Department of Zoology, University of Aberdeen, and to Dr C. Limpus for his comments on the manuscript. The author was employed as the Conservation Officer for Aldabra Atoll (1985-87), by the World Wide Fund for Nature and Seychelles Islands Foundation.

\section{References}

Bustard, H.R. and Greenham, P. 1968. Physical and chemical factors affecting hatching in the green sea turtle, Chelonia mydas (L.). Ecology, 49, 269-276.

Frazier, J. 1971. Observations on the sea turtles at Aldabra Atoll. Phil. Trans. Roy. Soc. Lond. B260, 373-410.

Frazier, J. 1976. Report on the sea turtles in the Seychelles area. J. mar. biol. Ass. India, 18, 179-241.

Gibson, T.S.H. 1979. Green turtle (Chelonia mydas [L.]) nesting activity at Aldabra Atoll. Phil. Trans. Roy. Soc. Lond. B286, 255-263.

Hendrickson, J.R. 1958. The green turtle, Chelonia mydas (Linn.) in Malaya and Sarawak. Proc. Zool. Soc. Lond. 130, 455-535.

Hirth, H. and Carr, A. 1970. The Green Turtle in the Gulf of Aden and the Seychelles Islands. Verh. K. neb. Akad. Wet, 58, 1-44.

Le Gall, J.Y., Bosc, P., Chateau, D. and Taquet, M. 1986. Estimation du nombre de tortues vertes femelles adultes Chelonia mydas par saison de pont a Tromelin et Europa (Ocean Indien) (1973-1985). Oceanogr. trop. 21(1), 3-22.

Meylan, A. 1982. Estimation of population size in sea turtles. In: Biology and Conservation of Sea Turtles (ed. K. A. Bjorndal), pp. 135-138. Smithsonian Institution Press, Washington, DC.

Mortimer, J.A. 1985. Recovery of green turtles on Aldabra. Oryx, 19, 146-150.

Mortimer, J.A. 1988. Green turtles nesting at Aldabra Atoll-population estimates and trends. Bull. Biol. Soc. Wash. 8, 116-128.

Seabrook, W. 1989. The seasonal pattern and distribution of green turtle (Chelonia mydas) nesting activity on Aldabra Atoll, Indian Ocean. J. Zool. Lond. 219, 71-81.

Stoddart, D.R. and Savy, S. 1983. Aldabra: Island of giant tortoises. Ambio, 12, (13-14), 180-185.

Wendy Seabrook, University of Sydney, School of Biological Sciences, NSW 2006, Australia. 